\title{
Experimental models and plant-based therapy for experimental cerebral ischemia (Review)
}

\author{
NADA M. EZZELARAB ${ }^{1 *}$, NAELA SALEH $^{1 *}$, EMAN A. KHALIL $^{2}$ and AHMED ABDELLATIF ${ }^{1,2}$ \\ ${ }^{1}$ Biotechnology Graduate Program, and ${ }^{2}$ Department of Biology, School of Sciences and Engineering, \\ The American University in Cairo, Cairo 11835, Egypt
}

Received May 13, 2020; Accepted August 10, 2020

DOI: $10.3892 /$ ijfn.2020.5

\begin{abstract}
Cerebral ischemia is a leading cause of mortality worldwide. Available treatments are mainly thrombolytic agents for restoring blood flow to the brain. However, this approach has a very narrow treatment window. Despite extensive research, there is still a need for further investigations to identify and develop novel treatment approaches. The present review aimed to summarize and discuss evidence from the literature regarding the best models with which to study cerebral ischemia and the available herbal sources that may provide potential treatment strategies for cerebral ischemia. The present review was based on research published between 1990 and 2020. Herbal remedies provide a promising research area that warrants further attention from researchers in the field. Different models have been used to investigate the pathophysiology of cerebral ischemia/reperfusion, and to examine various treatment approaches. The plant kingdom is rich in various phytochemicals with neuroprotective functions. From the literature search performed herein, it can be concluded that middle cerebral and bilateral common carotid artery occlusion models are the most convenient, cost-effective and easily reproducible models. A number of plants, particularly those from Southeast Asia, have used for cerebral ischemia research; however, many more need to be investigated, particularly plants from Africa.
\end{abstract}

Correspondence to: Dr Ahmed Abdellatif, Department of Biology, School of Sciences and Engineering, The American University in Cairo, Cairo 11835, Egypt

E-mail: ahmed.abdellatif@aucegypt.edu

*Contributed equally

Abbreviations: $\mathrm{BBB}$, blood-brain barrier; $\mathrm{BCCAO}$, bilateral common carotid artery occlusion; CCAs, common carotid arteries; MCA, middle cerebral artery; MCAO, middle cerebral artery occlusion; MRI, magnetic resonance imaging; SD, Sprague-Dawley; STAIR, Stroke Therapy Academic Industry Roundtable

Key words: cerebral ischemia, animal models, stroke, herbal medicine, cerebral ischemia/reperfusion

\section{Contents}

1. Introduction

2. Data collection methods

3. Search results

4. Assessment of functional deficits in cerebral ischemia models

5. Herbal remedies as neuroprotective agents in cerebral ischemia

6. Conclusions

\section{Introduction}

Cerebral ischemia occurs when the blood flow to the brain is restricted, and it claims the lives of millions worldwide $(1,2)$. In total, $16 \%$ of humans will have a stroke during their lifetime, with $>15$ million cases noted annually $(1,3)$. Stroke is a complex disease with a narrow time window for therapeutic intervention to restore the blood supply and prevent permanent brain tissue damage (2). As a result, currently available strategies are considered inadequate (2). Therefore, there is a need for further research in order to understand the pathophysiology of the disease and to identify techniques that can reduce its severe complications (2).

Clinically relevant models are essential for cerebral ischemia research. These models should be clinically relevant and reproducible to aid in the understanding of the pathophysiology of ischemic stroke, as well as to function as a platform for the development of novel therapeutic approaches for stroke treatment.

For a number of years, plants and natural remedies have been the primary tool for folk medicine. Medicinal plants provide a cost-effective source of drugs with significant therapeutic benefits and few side-effects in comparison to commercial synthetic drugs. Herbal remedies may provide a source of novel compounds that may present novel therapeutic tools for cerebral ischemia and stroke. However, with the variants of models of cerebral ischemia, the literature lacks the link between the efficacy of the plant and the model used, which may represent a possible strategy with which to understand the mechanisms of these natural remedies.

The present review aimed to summarize and discuss the literature for data related to animal models utilized in the 
research of cerebral ischemia, along with the herbal-based treatment approaches used in cerebral ischemia, in order to draw a full picture of the model used for treatment. The present review also aimed to illustrate the possible association between the natural ingredient in question that proved effective and the models of cerebral ischemia.

\section{Data collection methods}

Search strategy. Following the guidelines of Preferred Reporting Items For Systematic Reviews And Meta-Analyses (PRISMA) (4), the present review was conducted. The present review aimed to illustrate the data from peer-reviewed original articles on cerebral ischemia phytotherapy or from studies using in vivo models of cerebral ischemia. A search was conducted to obtain targeted articles through PubMed (https://pubmed. ncbi.nlm.nih.gov/) using the following keywords: 'Cerebral ischemia and herbal medicine'. The search span was between 1990 and 2020. In addition, the results were restricted to studies in the English language.

Selection criteria. The inclusion criteria were as follows: i) Only original studies between 1990 and 2020 were included in the present review; ii) any original article that assessed or used herbal extracts as a treatment approach for animal models of cerebral ischemia. On the other hand, the exclusion criteria were expanded to the following: i) Articles that reported the combination of plants as a formula/recipe; ii) research that was not published in the English language and were between 1990 and 2020; iii) case reports, review articles, or any secondary publications.

Data extraction. Search results were imported into Endnote X8 (Thompson Reuter) for the deletion of duplicates. The references were then screened by 3 reviewers, independently, using the eligibility criteria. The included articles were then reviewed, and data extraction was performed by 3 independent reviewers. Any disagreement in the extraction steps was raised to the supervisor to reach a consensus.

Risk of bias for individual studies. The included articles were investigated through the 'The Cochrane Collaboration's tool for assessing the risk of bias' (5). Any disagreements were discussed between authors to reach a consensus.

\section{Search results}

Search results and study characteristics. The search revealed 830 records; following title/abstract screening, 370 articles were selected. Following the screening of the full text of the articles, 52 studies were included in the present review.

Using the Cochrane risk of bias tool, we were uncertain of the bias regarding domains 4, 5 and 6 (5). However, most of the included studies showed a low risk of bias in the other domains.

Pathophysiology of cerebral ischemia. Ischemic stroke accounts for approximately $90 \%$ of all stroke cases in humans, followed by intracerebral hemorrhage $(9 \%)$ and subarachnoid hemorrhage (3\%). Ischemic stroke occurs due to the blockage of the middle cerebral artery (MCA). Cerebral tissue hypoxia and ischemia follow within minutes, leading to neuronal cell death and permanent damage to the brain (6). Thrombolytics and the rapid restoration of the blood supply remain the only treatment options with which to prevent further neuronal damage and decrease disability (6).

Ischemic damage to both white and grey matter causes permanent damage to brain tissue (7-9). Chronic cerebral hypoperfusion causes microglia/astrocyte activation, matrix metalloproteinase stimulation, blood-brain barrier disruption and endothelial abnormalities (10-12). Chronic cerebral hypoperfusion generates neuroinflammation, oxidative stress and apoptosis of the oligodendroglia (10-12). Aging, diabetes, atherosclerosis and hypertension are the most common risk factors that lead to chronic cerebral hypoperfusion (10-12).

In vitro models of cerebral ischemia. Testing different treatment approaches on human cells in vitro provides highly valuable, cost-effective and high-throughput systems for studies on stroke $(13,14)$. Although in vivo models are preferred in cerebral ischemia, genetic differences and structural variations, as well as molecular differences exist, which renders clinical translation problematic (13); therefore in vitro models are still critical for the understanding of the molecular mechanisms of the disease. With the introduction of new technologies, there is an excellent opportunity for the development of in vitro systems to model stroke and improve drug discovery (15). For a full review of the in vitro models of cerebral ischemia, please see the study by Holloway and Gavins, 2016 (15).

\section{Animal models in cerebral ischemia}

Brain structure and function: Humans vs. animals. Although there are apparent differences between the human brain and the brains of other species, animal studies are critical in translational research. The debate continues as to whether these differences render the use of animal models in stroke studies irrelevant to the clinical application (16). These differences are evident in infarct localization (16). Another significant difference is the amount of white matter in the brain. The white matter accounts for $60 \%$ of brain tissue in humans, compared to $35 \%$ in dogs, $20 \%$ in rabbits, $15 \%$ in rats and only $10 \%$ in mice (17). This white matter difference poses a problem, as the ischemic damage of the white matter is a key player in the pathophysiology of stroke in humans (18).

Small vs. large animal models in cerebral ischemia. A number of animal species are used to investigate the mechanisms underlying cerebral ischemia (19-22). Different methods are used to generate cerebral ischemia, such as bilateral common carotid artery (CCA) occlusion (BCCAO) in rats (19), bilateral CCA stenosis (20), or asymmetric CCA surgery in mice (21), and three-vessel occlusions (3VO) in primates (22). The pros and cons of these models are illustrated in Fig. 1.

The majority of the stroke preclinical studies are conducted using small animals, particularly rodents. These studies have assisted researchers in understanding the molecular and biochemical processes within the ischemic tissue (23), as well as in understanding the different aspects of the injury mechanisms (24). However, despite the ease of handling rodents and the cognitive impairment produced as a consequence of 


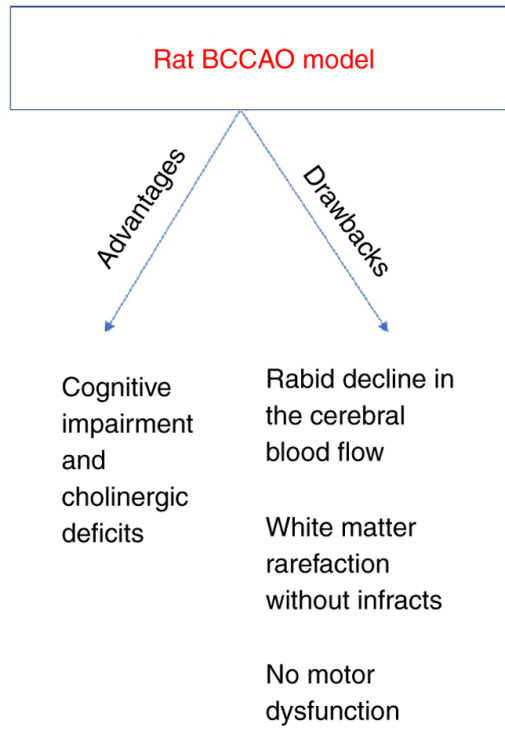

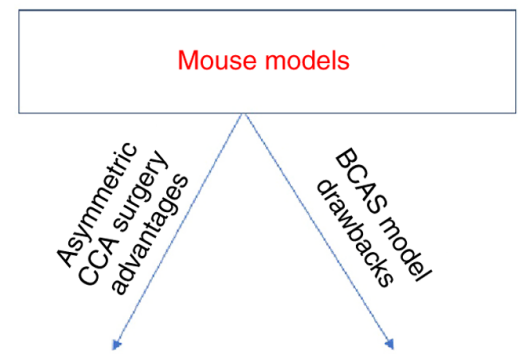

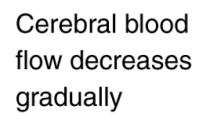

Observed motor dysfunction

Observed white matter infracts

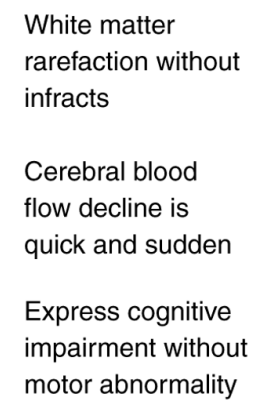

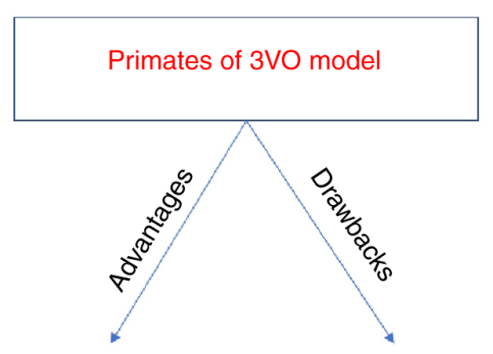

Mimics human

cerebral structure

High white matter percentage

Baboon illustrates tau pathology and amyloid beta deposition

Figure 1. Small vs. large animal models of cerebral ischemia. BCCAO, bilateral common carotid artery occlusion; CCA, common carotid artery; BCAS, bilateral common carotid artery stenosis; 3VO, 3-vessel occlusion.

chronic cerebral hypoperfusion, no motor abnormalities or white matter infarcts have been generated $(10,25,26)$.

The guidelines of the Stroke Therapy Academic Industry Roundtable (STAIR), dictate that clinical studies cannot be performed on humans before testing the new proposed pharmaceutical drugs on higher animal species (27-29). Nonetheless, the use large animal models in research is associated with various issues. One of these is the need for invasive surgery to generate and monitor ischemia and this causes a high mortality rate (24). Furthermore, large animal models are costly to maintain and are labor-intensive (24). Moreover, animal rights organizations have raised several concerns regarding the use of large animals (16).

One of the apparent advantages of using large animals, such as dogs, cats, pigs, sheep and primates (30) is that imaging is easier than with the use of small animals (31). It is also more suitable to monitor the physiology, e.g., blood pressure, and blood gases in large animals compared to small ones (24).

Another advantage is that the brain of large animals is similar to the human brain in terms of functionality and structure, i.e. gyrencephalic, while rodents have lissencephalic brains $(24,32)$. In addition, the ratio of the neocortex to the basal ganglia and the volume of white matter indicate that large animals are closer to the human neuroanatomy $(17,33,34)$. Furthermore, large animals are considerably similar to humans in several behavioral aspects, as well as sensorimotor integration (35). Primates exhibit similarities to humans regarding the cerebral structure and high white matter percentage $(29,36)$. Furthermore, the baboon 3-vessel occlusion (3VO) model has exhibited a tau pathology and amyloid- $\beta$ deposition similar to humans (37).

On the other hand, small animals, particularly rodents, are less costly to maintain compared to large animals $(17,38)$. Moreover, the rat physiology and cerebrovascular anatomy are similar to those of humans $(38,39)$, and mice have homogeneous genes, and as a result, genetic mutations are easily achievable to generate transgenic mice, commonly used to investigate the molecular pathophysiology of stroke $(40,41)$. The small brain size in rats and mice may be seen as an advantage, as various fixation procedures can be performed for neurochemical and biochemical investigations (21).

Methods used to induce cerebral ischemia in animal models. Ischemic stroke in humans occurs, in most cases, due to middle cerebral artery (MCA) occlusion (MCAO) (42). A number of models are designed to restrict cerebral blood flow, permanently or transiently, either directly by occlusion of the MCA or indirectly by common carotid artery ligation (43). A craniectomy is required for the direct occlusion of one or more cerebral vessels, through ligation, clipping, with hooks, or electrocoagulation (44). This model resembles human cases in terms of transient and permanent ischemia (44). Cerebral ischemia (CI) in this approach affects most of the cortices (45) and protects the thalamic, hypothalamic, hippocampal and midbrain regions from damage, since it produces small infarcts, unlike other MCAO models (45). It also creates a high percentage of infarct size and neurological deficits. The visual confirmation of successful MCAO is achieved during the surgery, with subsequent reperfusion of the ischemic areas (46).

On the other hand, this technique can lead to the injury of the underlying cortex or rupture of vessels by drilling or electrocoagulation (46). Additionally, the intracranial pressure and blood-brain barrier (BBB) function are greatly affected, and, as a result, it requires superior surgical skills (46). All in all, this method is highly invasive, with several complications. Therefore, other models have been introduced to avoid such complications.

MCAO models. This technique is similar to $70 \%$ of cerebral ischemic strokes that occur in humans $(33,47)$. 
Koizumi et al (48) first established the intraluminal suture technique in 1986 in rats, and it was modified in the 1990s for use in mice (49). The intraluminal suture model offers two options: Transient ischemia with reperfusion or a permanent occlusion based on the time in which the suture is left in place (50). A craniotomy is not required in this model (50). A significant disadvantage is that it stimulates a larger infarction beyond the MCA zone to spread to the hippocampus and thalamus (51).

This model is reproducible in terms of primary ischemic injury and, consequently, cell death, blood-brain barrier (BBB) damage and glial activation $(33,52)$. It is also appropriate for neuroprotection studies, due to the considerable existence of ischemic penumbra at the early stages post-occlusion (33). The infarct size in this model can be affected by the rat or mouse strain and the coating material for sutures. Strokes in spontaneously hypertensive rats (SHRs) are comparatively large and consistent in size. By contrast, in Sprague-Dawley (SD) rats, the infarcts are small and vary in size (53). An inadequate suture type may result in insufficient $\mathrm{MCAO}$, leading to vessel rupture and subsequent subarachnoid hemorrhage (SAH). Silicone or poly-l-lysine coating suture is more adherent to neighboring vascular endothelium, compared to the uncoated suture, which leads to larger infarcts and minimizes inter-animal variability $(54,55)$.

Unlike humans, following $60 \mathrm{~min}$ of MCAO, hypothalamic damage occurs (56). Following MCAO, hyperthermia occurs in rats and mice for at least 1 day due to hypothalamic ischemia $(56,57)$. Approximately $12 \mathrm{~h}$ is needed in the transient MCAO mouse model for the damage to be repaired and for recovery to take place, which is a long therapeutic time, unlike stroke in humans (58). These two different mechanisms in the two MCAO models lead to varying results, which may be the reasons for the failure of neuroprotective agents in clinical experiments (58).

$B C C A O$. In several human cases of stroke, cerebral ischemia is a complication of thromboembolic conditions, such as carotid artery stenosis (59), atrial fibrillation (60) and heart failure (61). The BCCAO model is a relatively rapid and easy rat model that can be used to produce temporary or chronic cerebral ischemia (25). Rats usually exhibit white matter damage accompanied by cognitive impairments resembling those associated with stroke in humans. However, the affection of the visual pathways following the rat BCCAO compromises behavioral assessments. Therefore, C57/B1 mice have been used instead of rats, since the mouse model does not cause visual impairment and is, therefore, suitable for behavioral studies. This model is relatively easy to use, and training researchers on this mouse model decreases the mortality rate to $<2 \%$.

The bilateral common carotid artery stenosis (BCAS) model is a modification that causes carotid stenosis; the severity of cerebral hypoperfusion can be easily controlled by changing the diameter of micro-coils inserted in the carotid artery. This model is used worldwide and can be regarded as one of the most promising models of chronic cerebral hypoperfusion $(10,20,62,63)$. This model mimics the white matter lesions induced by chronic cerebral hypoperfusion in humans (64).
Thromboembolic models. Thromboembolism is another cause of stroke. The thromboembolic clot model depends on the application route, the number and area of the clots (38). The thromboembolic clot can be spontaneous from autologous blood, which leads to vessel occlusion, causing infarcts (38). An advantage of this model is the spontaneous lysis of the clots, followed by reperfusion, which is similar to the case in humans (65).

An alternative method is the direct injection of thrombin into the MCA or internal carotid artery (ICA) to cause vascular occlusion (66). In this model, polymerized fibrin with a low number of cells and platelets are used to produce clots, while most of the human clots contain an accumulation of both platelets and fibrin, a deposition of neutrophils and monocytes and a high aggregation percentage of erythrocyte (67). In addition, the intravascular introduction of clots causes, in most cases, multifocal infarcts with noticeable variance in size and the localization of the lesion (68).

Another method with which to induce embolic stroke is by using microsphere/macrospheres to block blood flow. The major discrepancy with this model is that the fabricated spheres lead to permanent ischemia as they do not dissolve (65). An advantage associated with this model is the fact that the occlusion in rats may be postponed, while the animal is under monitor by PET or a magnetic resonance imaging (MRI) device (69).

Endothelin-1 model (ET-1). The reversible occlusion of the MCA can be achieved using a potent vasoconstrictor, such as endothelin-1 (ET-1) $(33,38,70,71)$. A rapid blood flow reduction to the brain can be noted after the ET-1 injection, followed by reperfusion several hours later (72). Occlusion can be achieved through various mechanisms, directly by topical application onto the exposed MCA, or by intracerebral injection (73). A primary advantage of the injection method is the low invasiveness and the low mortality rate. Although ET1 is effective in rats, it is not as effective in mice (74). Another problem with this model is the variability of the lesion size (75).

Photo thrombosis model. This model requires an intravenous injection in rats or an intraperitoneal injection in mice $(76,77)$ of a photosensitive dye, such as Rose Bengal or erythrosin B, followed by exposing the skull laser (78). Cerebral ischemia can be induced in specific brain regions depending on the purpose of the study. Once the dye is activated, reactive oxygen species (ROS) are generated, leading to endothelial damage, platelet activation and aggregation in pial and intraparenchymal vessels, forming thrombi (17). An advantage of this model is the rapid production of ischemic cell death (79). A further advantage is that it decreases the invasion and mortality rates. A significant disadvantage is that the ischemic injury is associated with early intracellular and extracellular edema formation (80), which differ from those observed in human stroke, as intracellular edema is the main indication of acute cerebral ischemia in humans (81).

In conclusion, as demonstrated through various sudies, there are various animal models, and associated techniques to produce cerebral ischemia/reperfusion, and each model has its advantages and weaknesses. The selection of the model should be based on the objectives and goal of the research study, bearing in mind that none of these models is identical to the human stroke pathophysiology. 


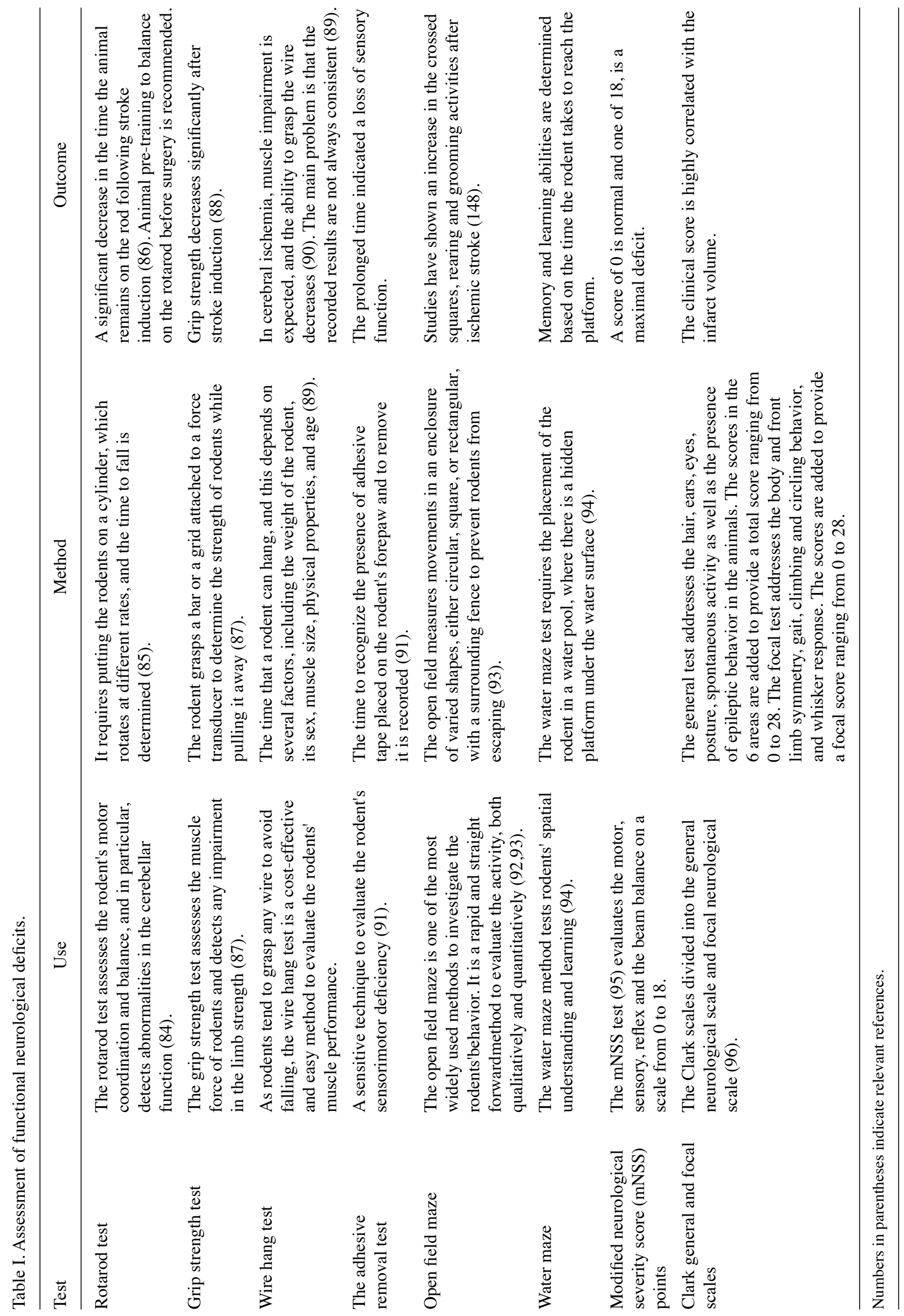




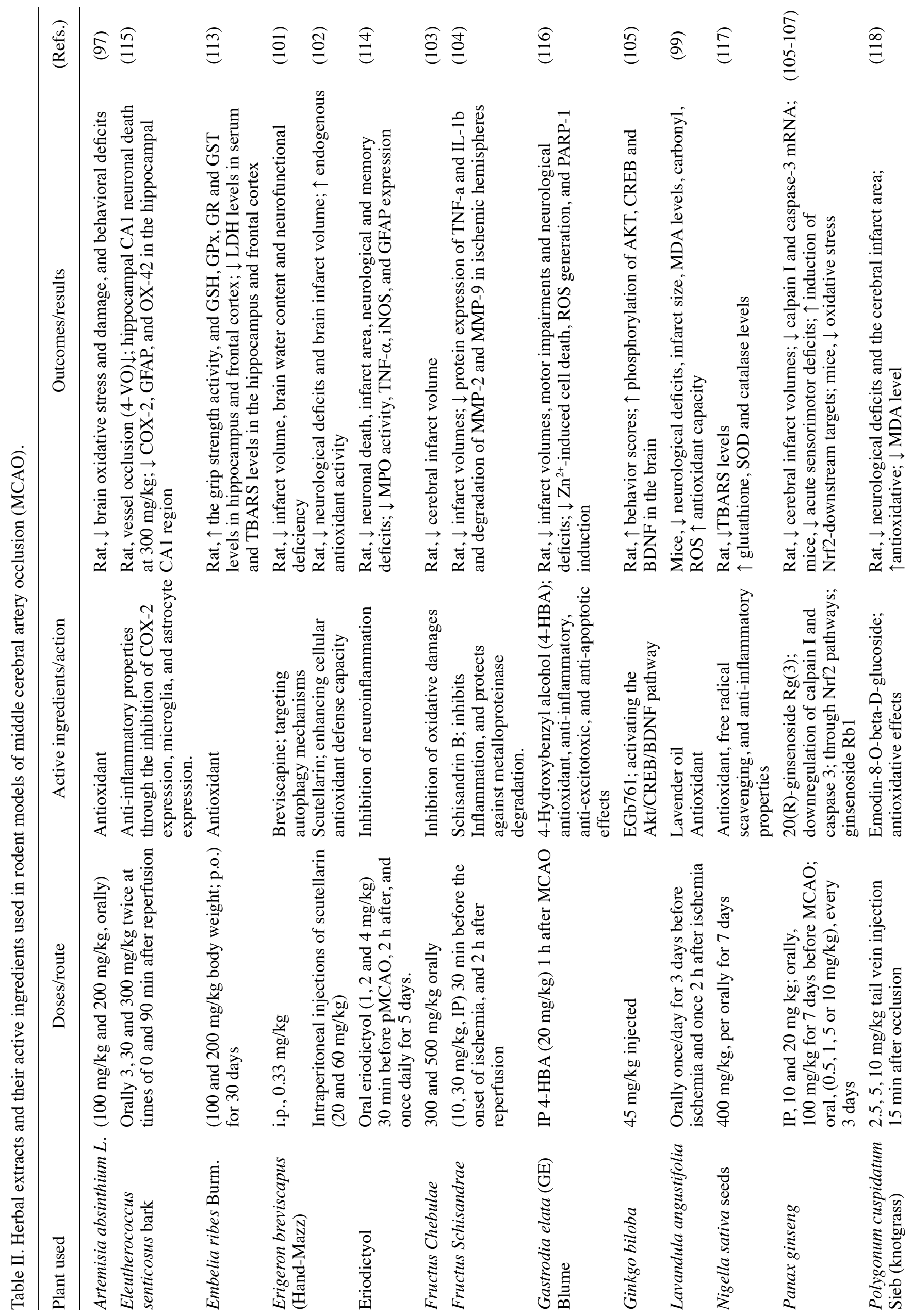




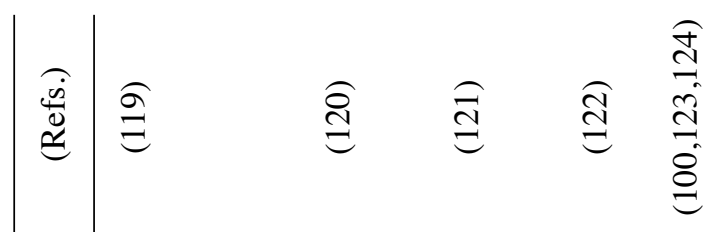

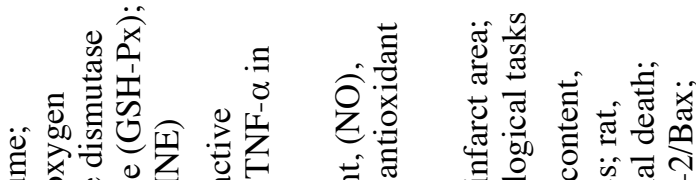

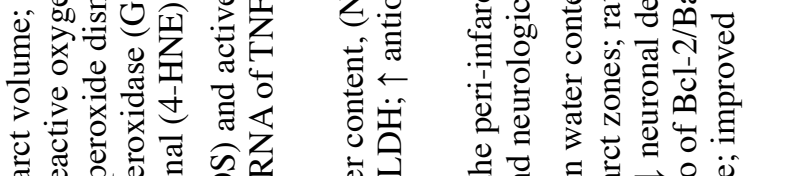

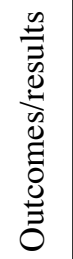

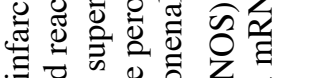

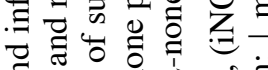

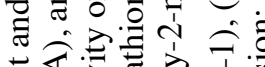

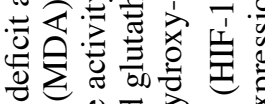

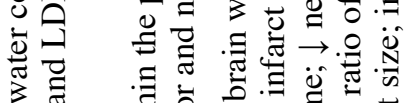

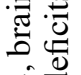

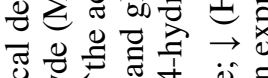

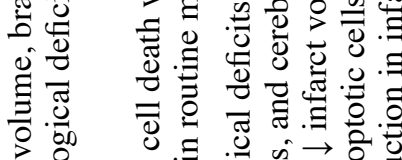

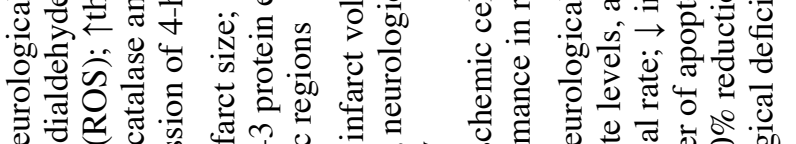

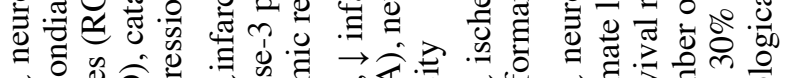

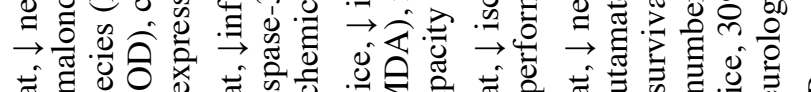

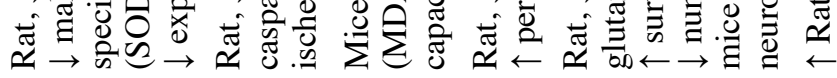

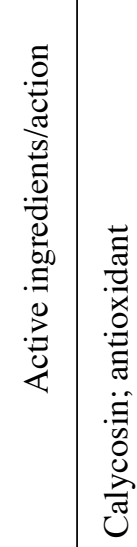

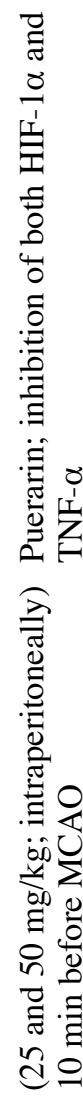

in

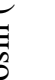

争

要

क्ष

是嵒

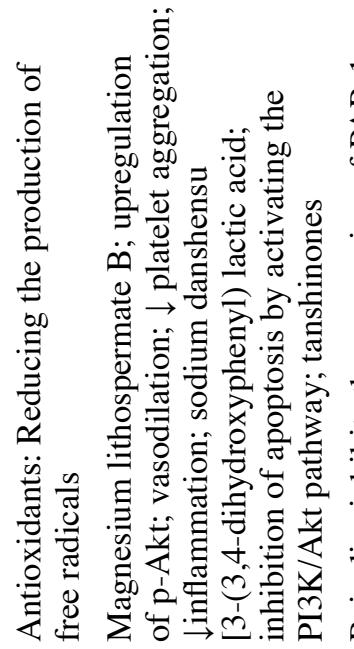

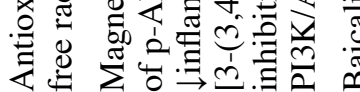

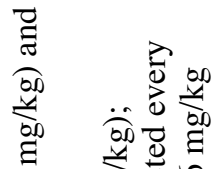

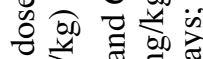

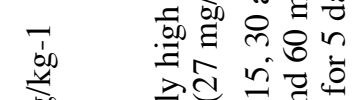

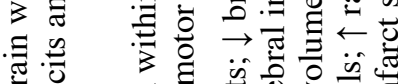

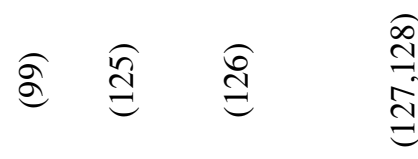

बิ

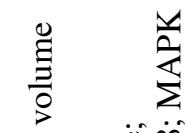

苟

क

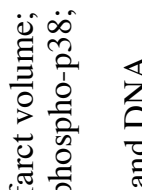

娄

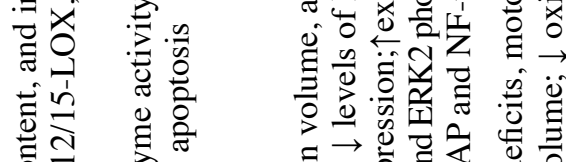

ठ항

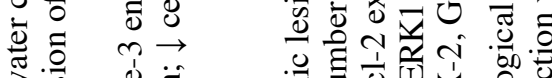

3.

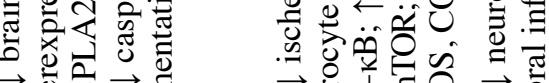

$\rightarrow$ 额 $\rightarrow$

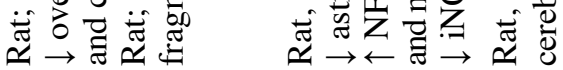

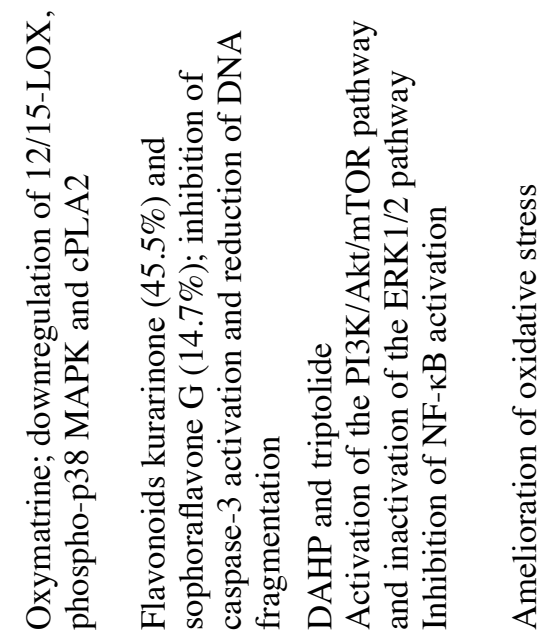

5.

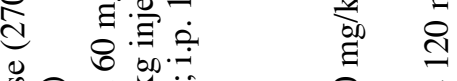

해

帝初

突

-

:

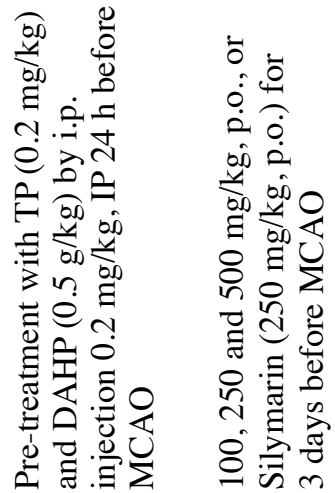

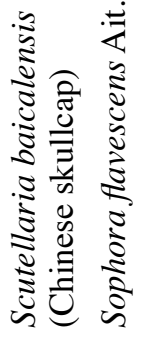

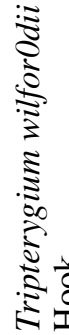

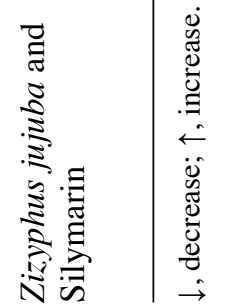




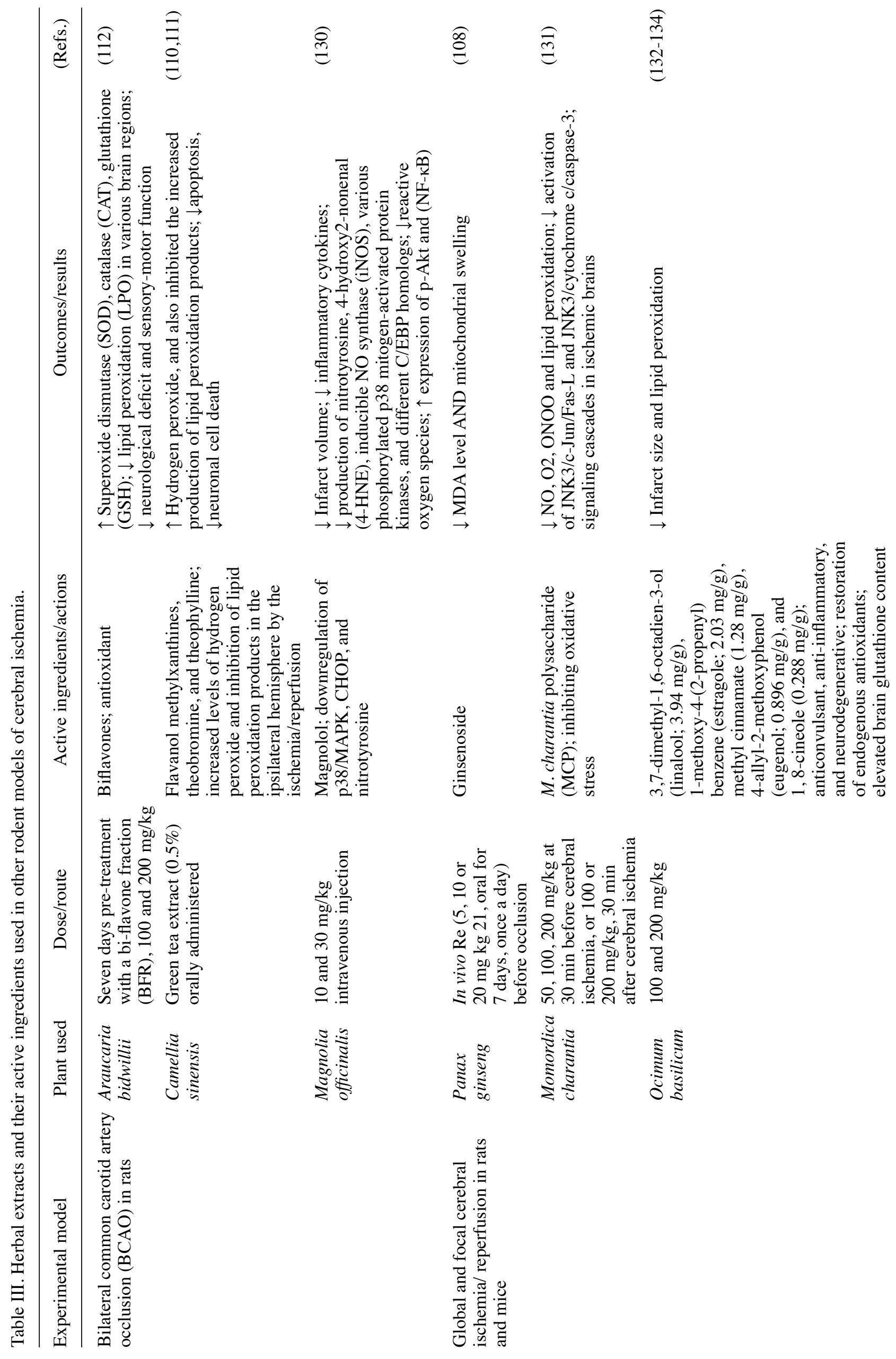




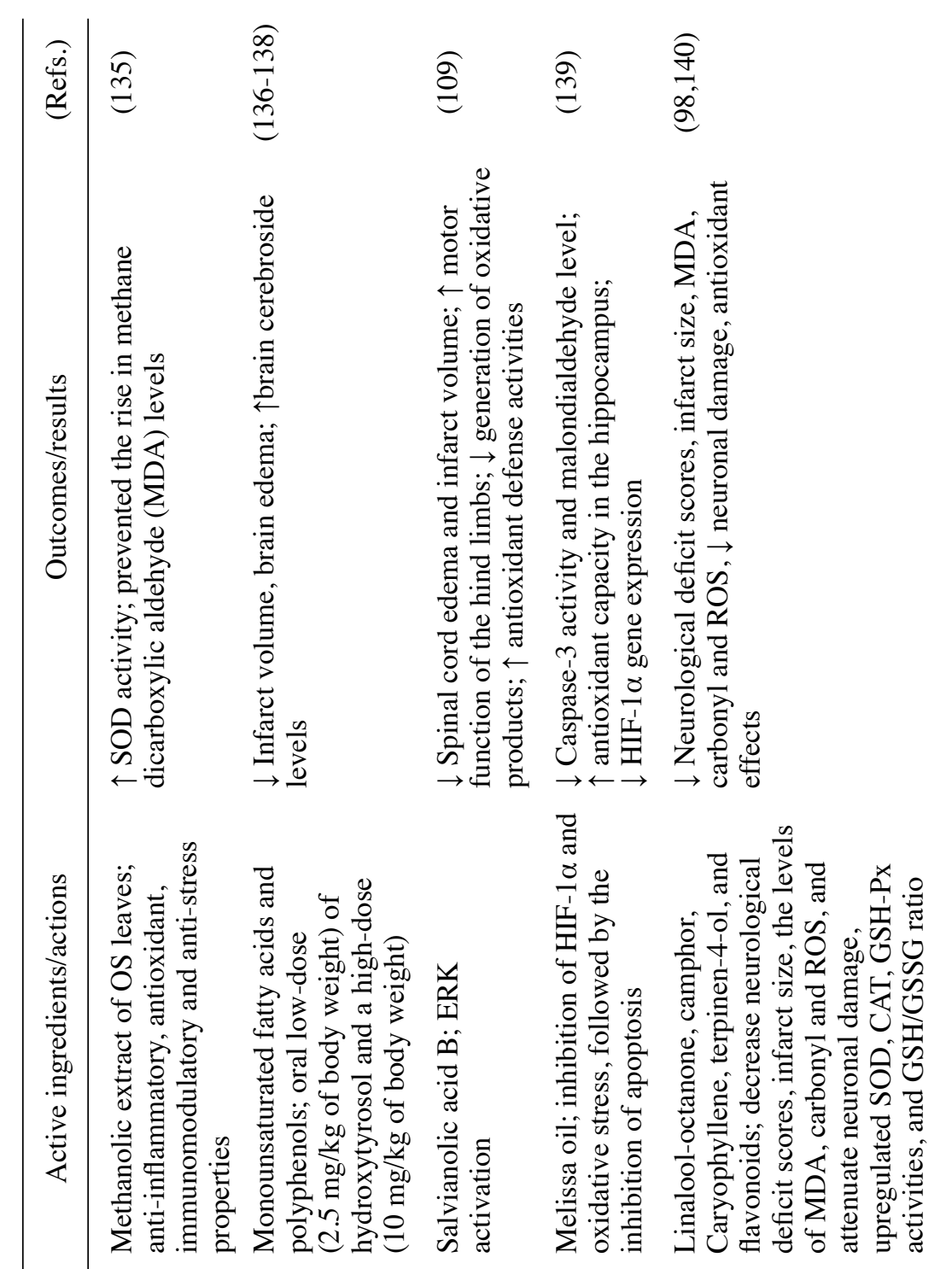

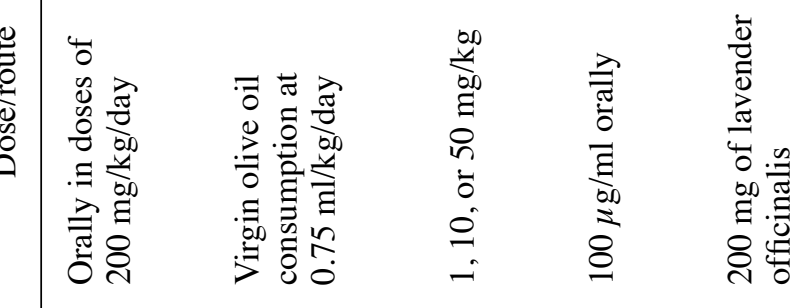
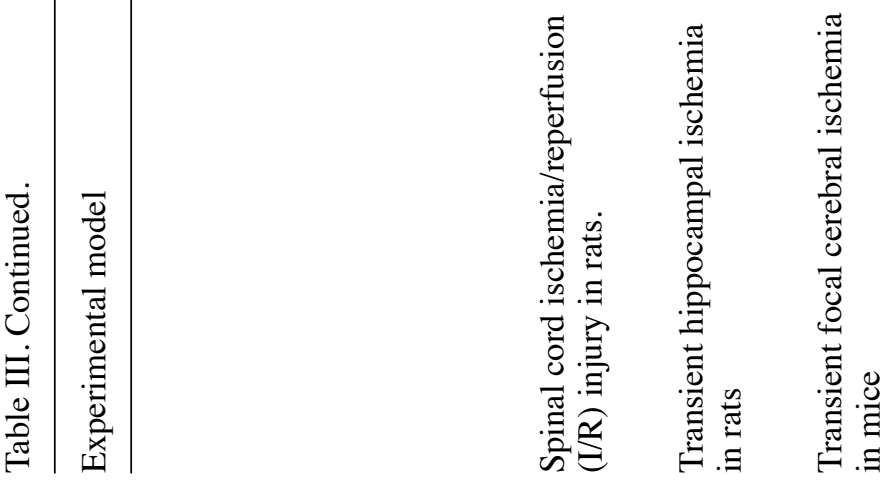

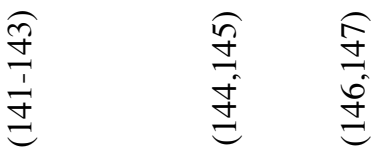
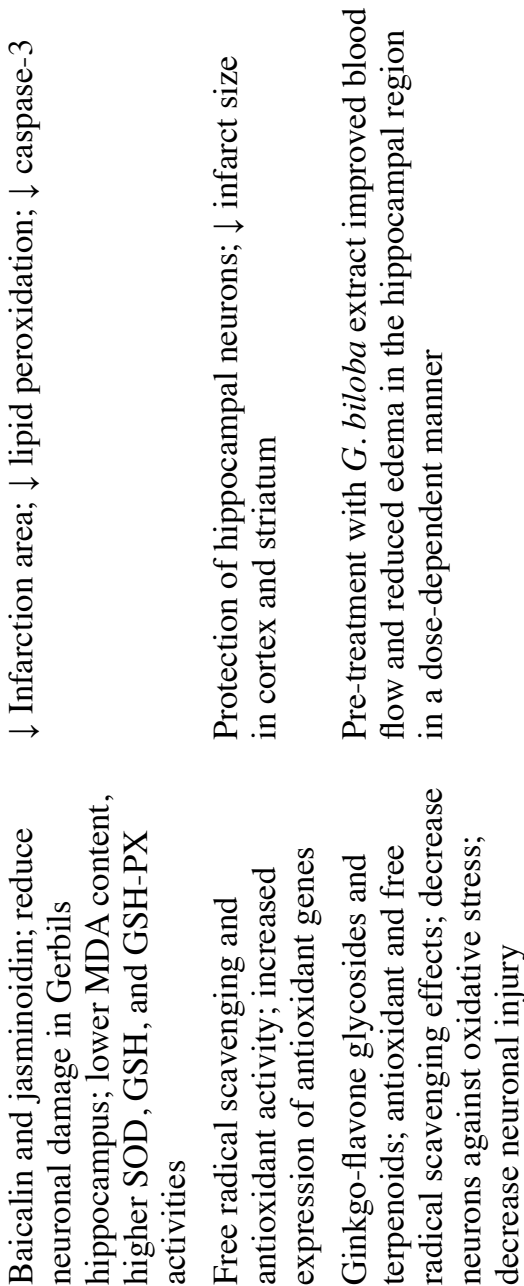

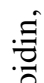

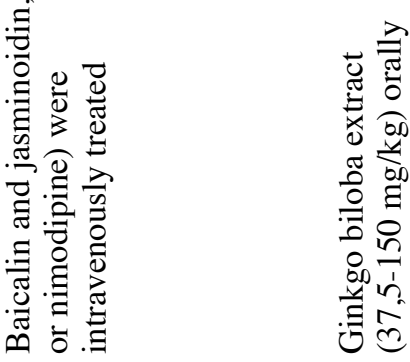

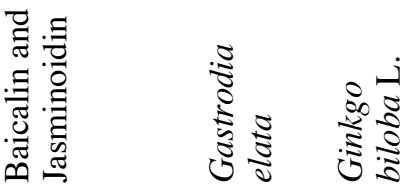

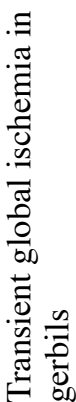




\section{Assessment of functional deficits in cerebral ischemia models}

Since stroke is associated with problems in the sensory and motor pathways, researchers have focused on studying the behavioral and cognitive aspects post-stroke (82). Various functional tests (Table I) are available for use in animals, including the Rotarod, the grip and string test, the wire hanging test, the adhesive removal test, the open field maze and the water maze test (83-95).

\section{Herbal remedies as neuroprotective agents in cerebral ischemia}

The MCAO model has been extensively studied with numerous natural herbal extracts. Cerebral ischemic injury results in the production of ROS, which cause lipid, DNA and protein oxidation, therefore causing cell damage and death (96). A number of these herbs possess antioxidant, anti-inflammatory and neuroprotective activity, such as Artemisia absinthium L. (97), Lavandula angustifolia (98), Scutellaria baicalensis (99) and several others. Their active ingredients exert significant neuroprotective effects and improvement in behavioral function when used before or after ischemic injury (98-100).

Chinese plants provide a rich source of herbal extracts for medicinal purposes. Some of these have been widely investigated in cerebral ischemia. Plants, such as Erigeron breviscapus $(101,102)$ contain breviscapine, which is considered to target autophagy mechanisms, leading to a reduction in infarct size and functional improvements in rats. Scutellarin is another component of Erigeron breviscapus, which exerts a decrease in infarct size and functional improvement when injected into rats (102). Other Chinese plants include Fructus Chebulae (103) and Fructus Schisandrae (Chinese magnolia vine fruit) (104), which protect against metalloproteinase degradation. In rats, these fruits lead to a reduction in the expression of TNF-a and IL-1b, as well as reduction in the degradation of the metalloproteinases, MMP-2 and MMP-9, in ischemic hemispheres, which leads to a reduction in infarct size (104). Panax ginseng (105-107) reduces infarcts size in rats and mice and improves function through the downregulation of calpain I and caspase 3 (107), and the induction of Nrf 2 downstream targets (106). Panax ginseng has also been used in global and focal ischemic models (108); it causes a decrease in lipid peroxidation and mitochondrial swelling (108).

Salvia miltiorrhiza is a potent antioxidant that is used in MCAO (100) and in spinal cord ischemia/reperfusion injury in rats (109). It exerts a decrease in edema and infarct volume, as well as functional improvements in both models. Antioxidants, such as Camellia sinensis $(110,111)$ and Araucaria bidwillii (112) cause functional improvements when used in global and focal ischemic models by inhibiting lipid peroxidation, and decreasing apoptosis and neuronal cell death.

Other herbal extracts and their active ingredients used in rodent models of MCAO are summarized in Table II (97-107,113-129). In Table III, the commonly used herbal extracts and their active ingredients used in other rodent models of cerebral ischemia are also listed $(98,108-112,130-147)$. The possible mechanisms of action of each are highlighted.

\section{Conclusions}

Different in vitro and animal models are available for the study of cerebral ischemia/reperfusion injury. The pathophysiology of cerebral ischemia/reperfusion is complex, and animal models are superior, particularly when testing various treatment approaches. It is suggested that the MCAO and BCCAO models the most convenient, cost-effective and easily reproducible models. Herbal extracts and phytochemicals provide a wide variety of neuroprotective agents that may be of value to research in cerebral ischemia. Further investigations are required to identify the active ingredients of such plants, and further testing is warranted. The literature provides a wealth of knowledge regarding herbal medicine in cerebral ischemia research, mostly using plants from south-East Asia. Plants from Africa and other regions warrant further investigation as they provide attractive targets for the development of novel therapeutic drugs.

\section{Acknowledgements}

Not applicable.

\section{Funding}

The present study was partially funded by a research support grant (SSE-BIOL-A.A-FY20) from the American University in Cairo.

\section{Availability of data and materials}

Data sharing is not applicable to this article, as no datasets were generated or analyzed during the current study.

\section{Authors' contributions}

NME, NS, EK, AA were involved in the conception and design of the study, and in the writing and revision of the manuscript. NE and NS were involved in the production of the figure and tables.

\section{Ethics approval and consent to participate}

Not applicable.

\section{Patient consent for publication}

Not applicable.

\section{Competing interests}

The authors declare that they have no competing interests.

\section{References}

1. Mozaffarian D, Benjamin EJ, Go AS, Arnett DK, Blaha MJ, Cushman M, de Ferranti S, Després JP, Fullerton HJ, Howard VJ, et al: Heart disease and stroke statistics-2015 update: A report from the American Heart Association. Circulation 131: e29-e322, 2015.

2. Dong B, Yang Y, Zhang Z, Xie K, Su L and Yu Y: Hemopexin alleviates cognitive dysfunction after focal cerebral ischemia-reperfusion injury in rats. BMC Anesthesiol 19: 13, 2019. 
3. Di Carlo A: Human and economic burden of stroke. Age Ageing 38: 4-5, 2009.

4. Moher D, Liberati A, Tetzlaff J and Altman DG: Preferred reporting items for systematic reviews and meta-analyses: The PRISMA statement. Ann Intern Med 151: 264-269, 2009.

5. Higgins JP, Altman DG, Gøtzsche PC, Jüni P, Moher D, Oxman AD, Savovic J, Schulz KF, Weeks L, Sterne JA, et al: The Cochrane Collaboration's tool for assessing risk of bias in randomised trials. BMJ 343: d5928, 2011.

6. Woodruff TM, Thundyil J, Tang SC, Sobey CG, Taylor SM and Arumugam TV: Pathophysiology, treatment, and animal and cellular models of human ischemic stroke. Mol Neurodegener 6: $11,2011$.

7. O'Brien JT and Thomas A: Vascular dementia. Lancet 386: 1698-1706, 2015

8. Kalaria RN: Neuropathological diagnosis of vascular cognitive impairment and vascular dementia with implications for Alzheimer's disease. Acta Neuropathol 131: 659-685, 2016.

9. Hainsworth AH and Markus HS: Do in vivo experimental models reflect human cerebral small vessel disease? A systematic review. J Cereb Blood Flow Metab 28: 1877-1891, 2008.

10. Bink DI, Ritz K, Aronica E, Van Der Weerd L and Daemen MJ Mouse models to study the effect of cardiovascular risk factors on brain structure and cognition. J Cereb Blood Flow Metab 33: $1666-1684,2013$

11. Gorelick PB, Counts SE and Nyenhuis D: Vascular cognitive impairment and dementia. Biochim Biophys Acta 1862: 860-868, 2016

12. Venkat P, Chopp M and Chen J: Models and mechanisms of vascular dementia. Exp Neurol 272: 97-108, 2015.

13. Hanke T: Lessons from TGN1412. Lancet 368: 1569-1570; author reply 1570, 2006.

14. Römer PS, Berr S, Avota E, Na SY, Battaglia M, ten Berge I, Einsele $\mathrm{H}$ and Hünig T: Preculture of PBMCs at high cell density increases sensitivity of T-cell responses, revealing cytokine release by CD28 superagonist TGN1412. Blood 118: 6772-6782, 2011.

15. Holloway PM and Gavins FN: Modeling ischemic stroke in vitro: status quo and future perspectives. Stroke 47: 561-569, 2016.

16. Cook DJ and Tymianski M: Nonhuman primate models of stroke for translational neuroprotection research. Neurotherapeutics 9 371-379, 2012.

17. Krafft PR, Bailey EL, Lekic T, Rolland WB, Altay O, Tang J, Wardlaw JM, Zhang JH and Sudlow CL: Etiology of stroke and choice of models. Int J Stroke 7: 398-406, 2012.

18. Ahmad AS, Satriotomo I, Fazal J, Nadeau SE and Doré S Considerations for the optimization of induced white matter injury preclinical models. Front Neurol 6: 172, 2015.

19. Edrissi H, Schock SC, Cadonic R, Hakim AM and Thompson CS : Cilostazol reduces blood brain barrier dysfunction, white matter lesion formation and motor deficits following chronic cerebral hypoperfusion. Brain Res 1646: 494-503, 2016.

20. Shibata M, Ohtani R, Ihara M and Tomimoto H: White matter lesions and glial activation in a novel mouse model of chronic cerebral hypoperfusion. Stroke 35: 2598-2603, 2004.

21. Hattori Y, Enmi J, Kitamura A, Yamamoto Y, Saito S, Takahashi Y, Iguchi S, Tsuji M, Yamahara K, Nagatsuka K, et al: A novel mouse model of subcortical infarcts with dementia. J Neurosci 35: 3915-3928, 2015.

22. Chen A, Akinyemi RO, Hase Y, Firbank MJ, Ndung'u MN Foster V, Craggs LJ, Washida K, Okamoto Y, Thomas AJ, et al: Frontal white matter hyperintensities, clasmatodendrosis and gliovascular abnormalities in ageing and post-stroke dementia Brain 139: 242-258, 2015

23. McCabe C, Arroja MM, Reid E and Macrae IM: Animal models of ischaemic stroke and characterisation of the ischaemic penumbra. Neuropharmacology 134: 169-177, 2018.

24. Traystman RJ: Animal models of focal and global cerebral ischemia. ILAR J 44: 85-95, 2003.

25. Farkas E, Luiten PG and Bari F: Permanent, bilateral common carotid artery occlusion in the rat: A model for chronic cerebral hypoperfusion-related neurodegenerative diseases. Brain Res Rev 54: 162-180, 2007.

26. Nishio K, Ihara M, Yamasaki N, Kalaria RN, Maki T, Fujita Y, Ito $\mathrm{H}$, Oishi N, Fukuyama H, Miyakawa T, et al: A mouse mode characterizing features of vascular dementia with hippocampal atrophy. Stroke 41: 1278-1284, 2010.

27. Stem Cell Therapies as an Emerging Paradigm in Stroke Participants: Stem cell therapies as an emerging paradigm in stroke (STEPS): Bridging basic and clinical science for cellular and neurogenic factor therapy in treating stroke. Stroke 40: 510-515, 2009.
28. Savitz SI, Chopp M, Deans R, Carmichael S, Phinney D and Wechsler L; STEPS Participants: Stem cell therapy as an emerging paradigm for stroke (STEPS) II. Stroke 42: 825-829, 2011.

29. Stroke Therapy Academic Industry Roundtable (STAIR): Recommendations for standards regarding preclinical neuroprotective and restorative drug development. Stroke 30: 2752-2758, 1999.

30. Bacigaluppi M, Comi G and Hermann DM: Animal models of ischemic stroke. Part two: Modeling cerebral ischemia. Open Neurol J 4: 34-38, 2010.

31. Marshall J, Ridley R, Baker H, Hall L, Carpenter T and Wood N: Serial MRI, functional recovery, and long-term infarct maturation in a non-human primate model of stroke. Brain Res Bull 61 577-585, 2003

32. Cook DJ, Teves L and Tymianski M: Treatment of stroke with a PSD-95 inhibitor in the gyrencephalic primate brain. Nature 483 213-217, 2012.

33. Howells DW, Porritt MJ, Rewell SS, O'collins V, Sena ES, Van Der Worp HB, Traystman RJ and Macleod MR: Different strokes for different folks: The rich diversity of animal models of focal cerebral ischemia. J Cereb Blood Flow Metab 30: $1412-1431,2010$.

34. Macrae I: Preclinical stroke research-advantages and disadvantages of the most common rodent models of focal ischaemia. Br J Pharmacol 164: 1062-1078, 2011.

35. Canazza A, Minati L, Boffano C, Parati E and Binks S: Experimental models of brain ischemia: A review of techniques, magnetic resonance imaging, and investigational cell-based therapies. Front Neurol 5: 19, 2014.

36. Madigan JB, Wilcock DM and Hainsworth AH: Vascular contributions to cognitive impairment and dementia: Topical review of animal models. Stroke 47: 1953-1959, 2016.

37. Ndung'u M, Härtig W, Wegner F, Mwenda J, Low R, Akinyemi R and Kalaria RN: Cerebral amyloid $\beta(42)$ deposits and microvascular pathology in ageing baboons. Neuropathol Appl Neurobiol 38: 487-499, 2012.

38. Durukan A and Tatlisumak T: Acute ischemic stroke: Overview of major experimental rodent models, pathophysiology, and therapy of focal cerebral ischemia. Pharmacol Biochem Behav 87: 179-197, 2007.

39. Liu F and McCullough LD: Middle cerebral artery occlusion model in rodents: Methods and potential pitfalls. J Biomed Biotechnol 2011: 464701, 2011.

40. Kraft P, Göb E, Schuhmann MK, Göbel K, Deppermann C, Thielmann I, Herrmann AM, Lorenz K, Brede M, Stoll G, et al: FTY720 ameliorates acute ischemic stroke in mice by reducing thrombo-inflammation but not by direct neuroprotection. Stroke 44: 3202-3210, 2013

41. Göb E, Reymann S, Langhauser F, Schuhmann MK, Kraft P, Thielmann I, Göbel K, Brede M, Homola G, Solymosi L, et al: Blocking of plasma kallikrein ameliorates stroke by reducing thromboinflammation. Ann Neurol 77: 784-803, 2015.

42. Dirnagl U and Macleod MR: Stroke research at a road block: The streets from adversity should be paved with meta-analysis and good laboratory practice. Br J Pharmacol 157: 1154-1156, 2009.

43. Yanamoto H, Nagata I, Niitsu Y, Xue JH, Zhang Z and Kikuchi H: Evaluation of MCAO stroke models in normotensive rats: Standardized neocortical infarction by the $3 \mathrm{VO}$ technique. Exp Neurol 182: 261-274, 2003

44. Dirnagl U: Rodent models of stroke: Springer, 2010.

45. Buchan AM, Xue D and Slivka A: A new model of temporary focal neocortical ischemia in the rat. Stroke 23: 273-279, 1992.

46. Sugimori H, Yao H, Ooboshi H, Ibayashi S and Iida M: Krypton laser-induced photothrombotic distal middle cerebral artery occlusion without craniectomy in mice. Brain Res Brain Res Protoc 13: 189-196, 2004

47. Bogousslavsky J, Van Melle G and Regli F: The Lausanne Stroke Registry: Analysis of 1,000 consecutive patients with first stroke. Stroke 19: 1083-1092, 1988

48. Koizumi J, Yoshida Y, Nakazawa T and Ooneda G: Experimental studies of ischemic brain edema. 1. A new experimental model of cerebral embolism in rats in which recirculation can be introduced in the ischemic area. Jpn J Stroke 8: 1-8, 1986.

49. Smith HK, Russell JM, Granger DN and Gavins FN: Critical differences between two classical surgical approaches for middle cerebral artery occlusion-induced stroke in mice. J Neurosci Methods 249: 99-105, 2015.

50. Chiang T, Messing RO and Chou WH: Mouse model of middle cerebral artery occlusion. J Vis Exp: e2761, 2011. 
51. Garcia JH, Liu KF and Ho KL: Neuronal necrosis after middle cerebral artery occlusion in Wistar rats progresses at different time intervals in the caudoputamen and the cortex. Stroke 26 : 636-643 Discussion 643, 1995

52. Kuraoka M, Furuta T, Matsuwaki T, Omatsu T, Ishii Y, Kyuwa S and Yoshikawa Y: Direct experimental occlusion of the distal middle cerebral artery induces high reproducibility of brain ischemia in mice. Exp Anim 58: 19-29, 2009.

53. Duverger D and MacKenzie ET: The quantification of cerebral infarction following focal ischemia in the rat: Influence of strain, arterial pressure, blood glucose concentration, and age. J Cereb Blood Flow Metab 8: 449-461, 1988.

54. Belayev L, Alonso OF, Busto R, Zhao W and Ginsberg MD: Middle cerebral artery occlusion in the rat by intraluminal suture. Neurological and pathological evaluation of an improved model. Stroke 27: 1616-1623, 1996.

55. Schmid-Elsaesser R, Zausinger S, Hungerhuber E, Baethmann A and Reulen HJ: A critical reevaluation of the intraluminal thread model of focal cerebral ischemia. Stroke 29: 2162-2170, 1998.

56. Li F, Omae T and Fisher M: Spontaneous hyperthermia and its mechanism in the intraluminal suture middle cerebral artery occlusion model of rats. Stroke 30: 2464-2470; Discussion 2470-2471, 1999.

57. Barber PA, Hoyte L, Colbourne F and Buchan AM: Temperatureregulated model of focal ischemia in the mouse: A study with histopathological and behavioral outcomes. Stroke 35: 1720-1725, 2004.

58. Hossmann KA: The two pathophysiologies of focal brain ischemia: Implications for translational stroke research. J Cereb Blood Flow Metab 32: 1310-1316, 2012.

59. Demarin V, Zavoreo I and Kes VB: Carotid artery disease and cognitive impairment. J Neurol Sci 322: 107-111, 2012.

60. de Bruijn RF, Heeringa J, Wolters FJ, Franco OH, Stricker BH, Hofman A, Koudstaal PJ and Ikram MA: Association between atrial fibrillation and dementia in the general population. JAMA Neurol 72: 1288-1294, 2015.

61. Adelborg K, Szépligeti S, Sundbøll J, Horváth-Puhó E, Henderson VW, Ording A, Pedersen L and Sørensen HT: Risk of stroke in patients with heart failure: A population-based 30-year cohort study. Stroke 48: 1161-1168, 2017.

62. Shibata M, Yamasaki N, Miyakawa T, Kalaria RN, Fujita Y, Ohtani R, Ihara M, Takahashi R and Tomimoto H: Selective impairment of working memory in a mouse model of chronic cerebral hypoperfusion. Stroke 38: 2826-2832, 2007.

63. Ihara M, Taguchi A, Maki T, Washida $\mathrm{K}$ and Tomimoto $\mathrm{H}$ A mouse model of chronic cerebral hypoperfusion characterizing features of vascular cognitive impairment. Methods Mol Biol 1135: 95-102, 2014

64. Washida K, Hattori Y and Ihara M: Animal models of chronic cerebral hypoperfusion: From mouse to primate. Int J Mol Sci 20: 6176, 2019.

65. Sommer CJ: Ischemic stroke: Experimental models and reality. Acta Neuropathol 133: 245-261, 2017.

66. Orset C, Macrez R, Young AR, Panthou D, Angles-Cano E, Maubert E, Agin V and Vivien D: Mouse model of in situ thromboembolic stroke and reperfusion. Stroke 38: 2771-2778, 2007.

67. Smith WS, Sung G, Starkman S, Saver JL, Kidwell CS, Gobin YP Lutsep HL, Nesbit GM, Grobelny T, Rymer MM, et al: Safety and efficacy of mechanical embolectomy in acute ischemic stroke: Results of the MERCI trial: Stroke 36: 1432-1438, 2005.

68. Niessen F, Hilger T, Hoehn M and Hossmann KA: Differences in clot preparation determine outcome of recombinant tissue plasminogen activator treatment in experimental thromboembolic stroke. Stroke 34: 2019-2024, 2003.

69. Walberer M and Rueger MA: The macrosphere model-an embolic stroke model for studying the pathophysiology of focal cerebral ischemia in a translational approach. Ann Transl Med 3: 123, 2015.

70. Macrae IM, Robinson MJ, Graham DI, Reid JL and McCulloch J: Endothelin-1-induced reductions in cerebral blood flow: Dose dependency, time course, and neuropathological consequences. J Cereb Blood Flow Metab 13: 276-284, 1993.

71. Bogaert L, Scheller D, Moonen J, Sarre S, Smolders I, Ebinger G and Michotte Y: Neurochemical changes and laser Doppler flowmetry in the endothelin-1 rat model for focal cerebral ischemia. Brain Res 887: 266-275, 2000.

72. Biernaskie J, Corbett D, Peeling J, Wells J and Lei H: A serial MR study of cerebral blood flow changes and lesion development following endothelin-1-induced ischemia in rats. Magn Reson Med 46: 827-830, 2001
73. Hughes PM, Anthony DC, Ruddin M, Botham MS, Rankine EL, Sablone M, Baumann D, Mir AK and Perry VH: Focal lesions in the rat central nervous system induced by endothelin-1. J Neuropathol Exp Neurol 62: 1276-1286, 2003.

74. Horie N, Maag AL, Hamilton SA, Shichinohe H, Bliss TM and Steinberg GK: Mouse model of focal cerebral ischemia using endothelin-1. J Neurosci Methods 173: 286-290, 2008.

75. Ansari S, Azari H, Caldwell KJ, Regenhardt RW, Hedna VS, Waters MF, Hoh BL and Mecca AP: Endothelin-1 induced middle cerebral artery occlusion model for ischemic stroke with laser Doppler flowmetry guidance in rat. J Vis Exp: 50014, 2013.

76. Kim GW, Sugawara T and Chan PH: Involvement of oxidative stress and caspase-3 in cortical infarction after photothrombotic ischemia in mice. J Cereb Blood Flow Metab 20: 1690-1701, 2000.

77. Kleinschnitz C, Braeuninger S, Pham M, Austinat M, Nölte I, Renné T, Nieswandt B, Bendszus M and Stoll G: Blocking of platelets or intrinsic coagulation pathway-driven thrombosis does not prevent cerebral infarctions induced by photothrombosis. Stroke 39: 1262-1268, 2008.

78. Watson BD, Dietrich WD, Busto R, Wachtel MS and Ginsberg MD: Induction of reproducible brain infarction by photochemically initiated thrombosis. Ann Neurol 17: 497-504, 1985.

79. Dietrich WD, Ginsberg MD, Busto $R$ and Watson BD Photochemically induced cortical infarction in the rat. 1. Time course of hemodynamic consequences. J Cereb Blood Flow Metab 6: 184-194, 1986.

80. Lee VM, Burdett NG, Carpenter A, Hall LD, Pambakian PS, Patel S, Wood NI and James MF: Evolution of photochemically induced focal cerebral ischemia in the rat. Magnetic resonance imaging and histology. Stroke 27: 2110-2119, 1996.

81. Provenzale JM, Jahan R, Naidich TP and Fox AJ: Assessment of the patient with hyperacute stroke: Imaging and therapy. Radiology 229: 347-359, 2003.

82. DeVries AC, Nelson RJ, Traystman RJ and Hurn PD: Cognitive and behavioral assessment in experimental stroke research: Will it prove useful? Neurosci Biobehav Rev 25: 325-342, 2001.

83. Shiotsuki H, Yoshimi K, Shimo Y, Funayama M, Takamatsu Y, Ikeda K, Takahashi R, Kitazawa S and Hattori N: A rotarod test for evaluation of motor skill learning. J Neurosci Methods 189: 180-185, 2010.

84. Balkaya M, Kröber JM, Rex A and Endres M: Assessing post-stroke behavior in mouse models of focal ischemia. J Cereb Blood Flow Metab 33: 330-338, 2013.

85. Lee JK, Park MS, Kim YS, Moon KS, Joo SP, Kim TS and Kim SH: Photochemically induced cerebral ischemia in a mouse model. Surg Neurol 67: 620-625, 2007.

86. De Luca A, Tinsley J, Aartsma-Rus A, van Putten M, Nagaraju K, de La Porte S, Dubach-Powell J and Carlson G: Use of grip strength meter to assess the limb strength of mdx mice. SOP DMD_M.2, 2008.

87. Ishrat T, Sayeed I, Atif F and Stein DG: Effects of progesterone administration on infarct volume and functional deficits following permanent focal cerebral ischemia in rats. Brain Res 1257: 94-101, 2009.

88. Hoffman $\mathrm{E}$ and Winder SJ: A modified wire hanging apparatus for small animal muscle function testing. PLoS Curr 8: ecurrents. md.1e2bec4e78697b7b0ff80ea25a1d38be, 2016.

89. Gerlai R, Thibodeaux H, Palmer JT, van Lookeren Campagne M and Van Bruggen N: Transient focal cerebral ischemia induces sensorimotor deficits in mice. Behav Brain Res 108: 63-71, 2000.

90. Bouet V, Boulouard M, Toutain J, Divoux D, Bernaudin M, Schumann-Bard P and Freret T: The adhesive removal test A sensitive method to assess sensorimotor deficits in mice. Nat Protoc 4: 1560-1564, 2009.

91. Seibenhener ML and Wooten MC: Use of the Open Field Maze to measure locomotor and anxiety-like behavior in mice. $\mathrm{J}$ Vis Exp: e52434,2015

92. Gould TD, Dao DT and Kovacsics CE: The open field test. Mood and anxiety related phenotypes in mice. Springer, pp1-20, 2009.

93. Vorhees CV and Williams MT: Morris water maze: Procedures for assessing spatial and related forms of learning and memory. Nat Protoc 1: 848-858, 2006.

94. Chen J, Sanberg PR, Li Y, Wang L, Lu M, Willing AE, Sanchez-Ramos J and Chopp M: Intravenous administration of human umbilical cord blood reduces behavioral deficits after stroke in rats. Stroke 32: 2682-2688, 2001 
95. Clark WM, Lessov NS, Dixon MP and Eckenstein F: Monofilament intraluminal middle cerebral artery occlusion in the mouse. Neurol Res 19: 641-648, 1997.

96. Niizuma K, Endo $\mathrm{H}$ and Chan PH: Oxidative stress and mitochondrial dysfunction as determinants of ischemic neurona death and survival. J Neurochem 109: 133-138, 2009.

97. Bora KS and Sharma A: Neuroprotective effect of Artemisia absinthium L. on focal ischemia and reperfusion-induced cerebral injury. J Ethnopharmacol 129: 403-409, 2010.

98. Wang D, Yuan X, Liu T, Liu L, Hu Y, Wang Z and Zheng Q: Neuroprotective activity of lavender oil on transient focal cerebral ischemia in mice. Molecules 17: 9803-9817, 2012.

99. Dai J, Qiu YM, Ma ZW, Yan GF, Zhou J, Li SQ, Wu H, Jin YC and Zhang XH: Neuroprotective effect of baicalin on focal cerebral ischemia in rats. Neural Regen Res 13: 2129-2133, 2018

100. Cao ZQ, Quan W, Hou SX, Guo C, Ma SB, Zhang W and Li X: The natural therapeutic magnesium lithospermate B potently provides neuroprotective effects on cerebral ischemia/reperfusion injury in rats. J Ethnopharmacol 162: 191-198, 2015

101. Pengyue Z, Tao G, Hongyun H, Liqiang Y and Yihao D Breviscapine confers a neuroprotective efficacy against transient focal cerebral ischemia by attenuating neuronal and astrocytic autophagy in the penumbra. Biomed Pharmacother 90: 69-76, 2017

102. Guo H, Hu LM, Wang SX, Wang YL, Shi F, Li H, Liu Y, Kang LY and Gao XM: Neuroprotective effects of scutellarin against hypoxic-ischemic-induced cerebral injury via augmentation of antioxidant defense capacity. Chin J Physiol 54 399-405, 2011.

103. Gaire BP and Kim HJ: Neuroprotective effects of Fructus Chebulae extracts on experimental models of cerebral ischemia J Tradit Chin Med 34: 69-75, 2014.

104.Lee TH, Jung CH and Lee DH: Neuroprotective effects of Schisandrin B against transient focal cerebral ischemia in Sprague-Dawley rats. Food Chem Toxicol 50: 4239-4245, 2012.

105. He B, Chen P, Yang J, Yun Y, Zhang X, Yang R and Shen Z: Neuroprotective effect of 20(R)-ginsenoside $\operatorname{Rg}(3)$ against transient focal cerebral ischemia in rats. Neurosci Lett 526: 106-111, 2012.

106. Liu L, Vollmer MK, Fernandez VM, Dweik Y, Kim H and Doré SJ: Korean red ginseng pretreatment protects against long-term sensorimotor deficits after ischemic stroke likely through Nrf2. Front Cell Neurosci 12: 74, 2018.

107. Dong X, Zheng L, Lu S and Yang YJ: Neuroprotective effects of pretreatment of ginsenoside Rb1 on severe cerebral ischemia-induced injuries in aged mice: Involvement of anti-oxidant signaling. Geriatr Gerontol Int 17: 338-345, 2017.

108. Chen LM, Zhou XM, Cao YL and Hu WX: Neuroprotection of ginsenoside $\mathrm{Re}$ in cerebral ischemia-reperfusion injury in rats. J Asian Nat Prod Res 10: 439-445, 2008.

109. Duan W, Wang L, Lv J, Gao K, Lu Y, Qin S, Ma X, Li J and Ge X: Metabolomics study on the effects of salvianolic acid B and borneol for treating cerebral ischemia in rats by ultra-performance liquid chromatography quadrupole time-of-flight mass spectrometry. Rejuvenation Res 22: 313-324, 2019.

110. Hong JT, Ryu SR, Kim HJ, Lee JK, Lee SH, Kim DB, Yun YP, Ryu JH, Lee BM and Kim PY: Neuroprotective effect of green tea extract in experimental ischemia-reperfusion brain injury. Brain Res Bull 53: 743-749, 2000.

111. Graham HN: Green tea composition, consumption, and polyphenol chemistry. Prev Med 21: 334-350, 1992.

112. Mukherjee PK, Ahamed KN, Kumar V, Mukherjee K and Houghton PJ: Protective effect of biflavones from Araucaria bidwillii Hook in rat cerebral ischemia/reperfusion induced oxidative stress. Behav Brain Res 178: 221-228, 2007.

113. Nazam Ansari M, Bhandari U, Islam F and Tripathi CD Evaluation of antioxidant and neuroprotective effect of ethanolic extract of Embelia ribes Burm in focal cerebral ischemia/reperfusion-induced oxidative stress in rats. Fundam Clin Pharmacol 22: 305-314, 2008.

114. Ferreira Ede O, Fernandes MY,Lima NM, Neves KR, Carmo MR, Lima FA, Fonteles AA, Menezes AP and Andrade GM: Neuroinflammatory response to experimental stroke is inhibited by eriodictyol. Behav Brain Res 312: 321-332, 2016.

115. Lee D, Park J, Yoon J, Kim MY, Choi HY and Kim HJ Neuroprotective effects of Eleutherococcus senticosus bark on transient global cerebral ischemia in rats. J Ethnopharmacol 139: $6-11,2012$
116. Luo L, Kim SW, Lee HK, Kim ID, Lee H and Lee JK: Anti- $\mathrm{Zn}^{2}+$-toxicity of 4-hydroxybenzyl alcohol in astrocytes and neurons contribute to a robust neuroprotective effects in the postischemic brain. Cell Mol Neurobiol 38: 615-626, 2018.

117. Akhtar M, Maikiyo AM, Najmi AK, Khanam R, Mujeeb M and Aqil M: Neuroprotective effects of chloroform and petroleum ether extracts of Nigella sativa seeds in stroke model of rat. J Pharm Bioallied Sci 5: 119, 2013.

118. Wang C, Zhang D, Ma H and Liu JJ: Neuroprotective effects of emodin-8-O-beta-d-glucoside in vivo and in vitro. Eur J Pharmacol 577: 58-63, 2007.

119. Guo C, Tong L, Xi M, Yang H, Dong H and Wen AJ: Neuroprotective effect of calycosin on cerebral ischemia and reperfusion injury in rats. Cell Physiol Biochem 144: 768-774, 2012.

120. Chang Y, Hsieh CY, Peng ZA, Yen TL, Hsiao G, Chou DS, Chen CM and Sheu JR: Neuroprotective mechanisms of puerarin in middle cerebral artery occlusion-induced brain infarction in rats. J Biomed Sci 16: 9, 2009.

121. Meng X, Xie W, Xu Q, Liang T, Xu X, Sun G and Sun X: Neuroprotective effects of radix scrophulariae on cerebral ischemia and reperfusion injury via MAPK pathways. Molecules 23: 2401,2018

122. Kaneko Y, Eve DJ, Yu S, Shojo H, Bae EC, Park DH, Roschek B Jr, Alberte RS, Sanberg PR, Sanberg CD, et al: Acute treatment with herbal extracts provides neuroprotective benefits in in vitro and in vivo stroke models, characterized by reduced ischemic cell death and maintenance of motor and neurological functions. Cell Med 1: 137-142, 2010.

123. Guo C, Yin Y, Duan J, Zhu Y, Yan J, Wei G, Guan Y, Wu X, Wang $\mathrm{Y}, \mathrm{Xi} \mathrm{M}$ and Wen $\mathrm{A}$ : Neuroprotective effect and underlying mechanism of sodium danshensu [3-(3,4-dihydroxyphenyl) lactic acid from Radix and Rhizoma Salviae miltiorrhizae $=$ Danshen] against cerebral ischemia and reperfusion injury in rats. Phytomedicine 22: 283-289, 2015.

124. Lam BY, Lo AC, Sun X, Luo HW, Chung SK and Sucher NJ: Neuroprotective effects of tanshinones in transient focal cerebral ischemia in mice. Phytomedicine 10: 286-291, 2003.

125. Cui L, Zhang X, Yang R, Wang L, Liu L, Li M and Du W: Neuroprotection and underlying mechanisms of oxymatrine in cerebral ischemia of rats. Neurol Res 33: 319-324, 2011.

126.Park S, Nam K, Lee H, Cho EY, Koo U and Mar W: Neuroprotective effects of an alkaloid-free ethyl acetate extract from the root of Sophora flavescens Ait. against focal cerebral ischemia in rats. Phytomedicine 16: 1042-1051, 2009.

127. Li W, Yang Y, Hu Z, Ling S and Fang M: Neuroprotective effects of DAHP and Triptolide in focal cerebral ischemia via apoptosis inhibition and PI3K/Akt/mTOR pathway activation. Front Neuroanat 9: 48, 2015

128. Lee HF, Lee TS and Kou YR: Anti-inflammatory and neuroprotective effects of triptolide on traumatic brain injury in rats. Respir Physiol Neurobiol 182: 1-8, 2012.

129. Gupta S and Gupta YK: Combination of Zizyphus jujuba and silymarin showed better neuroprotective effect as compared to single agent in MCAo-induced focal cerebral ischemia in rats. J Ethnopharmacol 197: 118-127, 2017.

130. Chen JH, Kuo HC, Lee KF and Tsai TH: Magnolol protects neurons against ischemia injury via the downregulation of p38/MAPK, CHOP and nitrotyrosine. Toxicol Appl Pharmacol 279: 294-302, 2014.

131. Gong J, Sun F, Li Y, Zhou X, Duan Z, Duan F, Zhao L, Chen H, Qi S and Shen J: Momordica charantia polysaccharides could protect against cerebral ischemia/reperfusion injury through inhibiting oxidative stress mediated c-Jun N-terminal kinase 3 signaling pathway. Neuropharmacology 91: 123-134, 2015.

132. Bora KS, Arora S and Shri R: Role of Ocimum basilicum L. in prevention of ischemia and reperfusion-induced cerebral damage, and motor dysfunctions in mice brain. J Ethnopharmacol 137: 1360-1365, 2011.

133. Dringen R: Metabolism and functions of glutathione in brain. Prog Neurobiol 62: 649-671, 2000.

134. Siddiqui BS, Aslam H, Ali ST, Begu S and Khatoon N: Two new triterpenoids and a steroidal glycoside from the aerial parts of Ocimum basilicum. Chem Pharm Bull (Tokyo) 55: 516-519, 2007.

135. Yanpallewar S, Rai S, Kumar M and Acharya SB: Evaluation of antioxidant and neuroprotective effect of Ocimum sanctum on transient cerebral ischemia and long-term cerebral hypoperfusion. Pharmacol Biochem Behav 79: 155-164, 2004. 
136. Fki I, Sahnoun Z and Sayadi S: Hypocholesterolemic effects of phenolic extracts and purified hydroxytyrosol recovered from olive mill wastewater in rats fed a cholesterol-rich diet. J Agric Food Chem 55: 624-631, 2007.

137. Mohagheghi F, Bigdeli MR, Rasoulian B, Zeinanloo AA and Khoshbaten A: Dietary virgin olive oil reduces blood brain barrier permeability, brain edema, and brain injury in rats subjected to ischemia-reperfusion. ScientificWorldJournal 10: 180-191, 2010.

138. Rabiei Z, Bigdeli MR and Rasoulian B: Neuroprotection of dietary virgin olive oil on brain lipidomics during stroke. Curr Neurovasc Res 10: 231-237, 2013.

139. Bayat M, Azami Tameh A, Hossein Ghahremani M, Akbari M, Mehr SE, Khanavi M and Hassanzadeh G: Neuroprotective properties of Melissa officinalis after hypoxic-ischemic injury both in vitro and in vivo. Daru 20: 42, 2012.

140. Rabiei Z and Rafieian-Kopaei M: Neuroprotective effect of pretreatment with Lavandula officinalis ethanolic extract on blood-brain barrier permeability in a rat stroke model. Asian Pac J Trop Med 7S1: S421-S426, 2014.

141. Cao Y, Maoa X, Sun C, Zheng P, Gao J, Wang X, Min D, Sun H, Xie N and Cai J: Baicalin attenuates global cerebral ischemia/reperfusion injury in gerbils via anti-oxidative and anti-apoptotic pathways. Brain Res Bull 85: 396-402, 2011.

142. Han BH, D'Costa A, Back SA, Parsadanian M, Patel S, Shah AR, Gidday JM, Srinivasan A, Deshmukh M and Holtzman DM: BDNF blocks caspase-3 activation in neonatal hypoxia-ischemia. Neurobiol Dis 7: 38-53, 2000.

143. Zhang ZJ, Li P, Wang Z, Li PT, Zhang WS, Sun ZH, Zhang XJ and Wang YY: A comparative study on the individual and combined effects of baicalin and jasminoidin on focal cerebral ischemia-reperfusion injury. Brain Res 1123: 188-195, 2006.
144. Kim HJ, Lee SR and Moon KD: Ether fraction of methanol extracts of Gastrodia elata, medicinal herb protects against neuronal cell damage after transient global ischemia in gerbils. Phytother Res 17: 909-912, 2003.

145. Yu SJ, Kim JR, Lee CK, Han JE, Lee JH, Kim HS, Hong JH and Kang SG: Gastrodia elata blume and an active component, p-hydroxybenzyl alcohol reduce focal ischemic brain injury through antioxidant related gene expressions. Biol Pharm Bull 28: 1016-1020, 2005.

146. Joyeux M, Lobstein A, Anton R and Mortier F: Comparative antilipoperoxidant, antinecrotic and scavenging properties of terpenes and biflavones from Ginkgo and some flavonoids. Planta Med 61: 126-129, 1995.

147. Calapai G, Crupi A, Firenzuoli F, Marciano MC, Squadrito F, Inferrera G, Parisi A, Rizzo A, Crisafulli C, Fiore A and Caputi AP: Neuroprotective effects of Ginkgo biloba extract in brain ischemia are mediated by inhibition of nitric oxide synthesis. Life Sci 67: 2673-2683, 2000.

148. Yan XB, Wang SS, Hou HL, Ji R and Zhou JN: Lithium improves the behavioral disorder in rats subjected to transient global cerebral ischemia. Behav Brain Res 177: 282-289, 2007.

(i) $($ This work is licensed under a Creative Commons Attribution-NonCommercial-NoDerivatives 4.0 International (CC BY-NC-ND 4.0) License. 